\title{
Aripiprazole-Induced Acute Transient Bilateral Myopia: A Case Report
}

\author{
(D) Yunus Bulgu, ${ }^{1}$ (D) Selim Genc ${ }^{2}$ \\ 1Department of Ophthalmology, Sancaktepe Sehit Prof. Dr. Ilhan Varank Training and Research Hospital, Istanbul, Turkey \\ 2Department of Ophthalmology, Beyoğlu Eye Research and Training Hospital, Istanbul, Turkey
}

\begin{abstract}
Aripiprazole is an atypical, antipsychotic drug used for the treatment of schizophrenia, depression, bipolar disorder, and obsessive-compulsive disorder in adults. There are a few reports in the literature of ocular side effects of aripiprazole, such as transient myopia, diplopia, and acute angle closure. This report describes the case of a 34-year-old female patient who was referred to the clinic with painless blurred vision in both eyes. She had been diagnosed with major depression and had been using aripiprazole for a month. She experienced blurred vision after the first week of drug therapy. The uncorrected visual acuity (UCVA) was 4/I0 in both eyes using a standard Snellen chart. She had a refractive error of -2.00 diopters and the best corrected visual acuity was $10 / 10$ in both eyes. The ocular examination results were normal other than the refractive error. The patient was diagnosed with aripiprazole-induced, acute transient myopia. The UCVA was $10 / 10$ in both eyes at the 2-week follow-up following termination of the aripiprazole therapy. It is important to be prepared to recognize aripiprazole-induced, acute transient myopia in patients complaining about blurred vision.
\end{abstract}

Keywords: Aripiprazole, ciliochoroidal effusion, myopia.

\section{Introduction}

Aripiprazole is a second-generation antipsychotic. The efficacy of aripiprazole has been primarily attributed to a combination of partial agonism at the human dopamine D2 and serotonin 5-HTIA receptors and antagonism at the serotonin $5-\mathrm{HT} 2 \mathrm{~A}$ receptors. The drug is used in the treatment of schizophrenia, depression, bipolar disorder, and obsessive-compulsive disorder (I). Common adverse effects include insomnia, fatigue, constipation, akathisia, headache, nausea, vomiting, weight gain, and somnolence (2). Ocular side effects of aripiprazole, such as transient myopia, diplopia, acute angle closure, and chorioretinopathy, have been reported to occur, albeit rarely. To our knowledge there are only a few cases of aripiprazole-related diplopia in the literature (3-7).

\section{Case Report}

A 34-year-old female patient was using oral escitalopram and aripiprazole for major depression. The patient was admitted to the clinic for painless blurred vision in both eyes, which had started in the first week following the use of adjunctive aripiprazole therapy. Her uncorrected visual acuity (UCVA) was $4 / 10$ and her best corrected visual acuity was $10 / 10$ in both eyes with a refractive error of -2.00 diopters. She did not have a previous optical prescription. The anterior chamber and fundus examination was bilaterally normal. The intraocular pressure was bilaterally $18 \mathrm{mmHg}$ and the anterior chamber angles were open. The patient did not have any other systemic disease. The diagnosis was aripiprazole-induced, acute transient myopia. Two weeks after discontinuing the aripiprazole treatment, the UCVA had improved to 20/20.

Address for correspondence: Yunus Bulgu, MD. Sancaktepe Sehit Prof. Dr. Ilhan Varank Egitim ve Arastirma Hastanesi, 34540 Istanbul, Turkey

Phone: +90 5544149757 E-mail: drbulguy82@hotmail.com

Submitted Date: November 28, 2019 Accepted Date: February 02, 2020 Available Online Date: February 17, 2020

${ }^{\circ}$ Copyright 2020 by Beyoglu Eye Training and Research Hospital - Available online at www.beyoglueye.com OPEN ACCESS This work is licensed under a Creative Commons Attribution-NonCommercial 4.0 International License. 
Aripiprazole is a second generation antipsychotic that acts as a potent partial agonist at the dopamine D2, D3, and serotonin (5-HT/5-hydroxytryptamine) 5 -HTIA receptors and as an antagonist at the $5-\mathrm{HT} 2 \mathrm{~A}$ receptors ( $\mathrm{I})$. Many drugs may cause acute transient myopia (5). There are some reports of mechanisms of drug-induced myopia in the literature, such as ciliary spasm, accommodation spasm, ciliary body effusion, increasing thickness of the lens, and peripheral uveal effusion (4). An idiosyncratic reaction from the use of a drug can result in swelling of the ciliary body and ciliochoroidal effusion. Choroidal blood flow dysregulation may induce fluid accumulation at the ciliary body. Myopia can be a result of anterior rotation of the ciliary processes causing forward displacement of the iris and lens. Movement of the iris-lens diaphragm anteriorly reduces zonular tension and allows for subtle lens thickening. These factors are thought to be responsible for an acute myopic shift (8-10).

Kaya et al. (3) reported the case of a 21 -year-old female who had been diagnosed with bipolar affective disorder and was receiving sodium valproate treatment. Oral aripiprazole $15 \mathrm{mg}$ was added when she presented with manic symptoms. Seven days after the introduction of aripiprazole, she developed myopia in both eyes. Upon termination of aripiprazole use, the myopia resolved in 10 days.

Selvi et al. (4) reported an aripiprazole-related myopia case in a 19-year-old female with obsessive compulsive symptoms. She developed myopia in both eyes and diplopia 2 weeks after initiation of aripiprazole therapy. Ten days after cessation of the drug, the symptoms resolved.

Nair et al. (5) described an aripiprazole-related myopia case in a 33-year-old male with schizophrenia. One month after the addition of oral $15 \mathrm{mg}$ aripiprazole, he developed myopia in both eyes. The myopia disappeared 10 days after he stopped taking the drug.

Karadag et al. (6) reported an aripiprazole-related myopia case in a 30-year-old male with schizophrenia. Aripiprazole was administered at a $20 \mathrm{mg} /$ daily dosage. On the fifth day of the aripiprazole treatment, the patient reported that he had blurred vision and developed myopia in both eyes. After discontinuation of aripiprazole treatment and cross-tapering to paliperidone palmitate $(75 \mathrm{mg} / \mathrm{month})$ the blurred vision completely resolved.

Kumar et al. (7) reported a case in a 22-year-old female patient who presented at the department of psychiatry with worsening of symptoms of schizophrenia and was started on aripiprazole. She returned with complaints of blurring of vision in both eyes for I week that had begun on the third day of the aripiprazole treatment.

The diagnosis of our patient was acute and transient myopia related to aripiprazole. The rapid resolution of these conditions after discontinuation of aripiprazole suggests a correlation between use and the adverse effect. It is important for clinicians to recognize these conditions and warn patients about these ocular adverse effects when prescribing aripiprazole. Ophthalmologists should be aware of this potential ocular adverse effect that may occur during drug therapy and should consult with the prescribing psychiatrist about changing the drug treatment.

This case report was presented as a poster at the Turkish Ophthalmology Society $52^{\text {nd }}$ Congress, November 13-18, 2018.

\section{Disclosures}

Informed Consent: Written informed consent was obtained from the patient for the publication of the case report.

Peer-review: Externally peer-reviewed.

Conflict of Interest: None declared.

Authorship Contributions: Involved in design and conduct of the study (YB, SG); preparation and review of the study (YB, SG); data collection (YB).

\section{References}

I. Shapiro DA, Renock S, Arrington E, Chiodo LA, Liu LX, Sibley $D R$, et al. Aripiprazole, a novel atypical antipsychotic drug with a unique and robust pharmacology. Neuropsychopharmacology 2003;28:1400-11.

2. Luan S, Wan H, Zhang L, Zhao H. Efficacy, acceptability, and safety of adjunctive aripiprazole in treatment-resistant depression: a meta-analysis of randomized controlled trials. Neuropsychiatr Dis Treat 2018;14:467-77.

3. Kaya $\mathrm{H}$, Yllbas B, Dilbaz N, Yazar Z. Aripiprazole induced acute myopia: A case report. Bull Clin Psychopharmacol 2009;19:147-8.

4. Selvi Y, Atli A, Aydin A, Yener HI. Aripiprazole-related acute transient myopia and diplopia: A case report. J Clin Psychopharmacol 201 I;31:249-50.

5. Nair AG, Nair AG, George RJ, Biswas J, Gandhi RA. Aripiprazole induced transient myopia: $A$ case report and review of literature. Cutan Ocul Toxicol 2012;3 I:74-6.

6. Karadağ H, Acar M, Özdel K. Aripiprazole induced acute transient bilateral myopia: A Case report. Balkan Med J 2015;32:230-2.

7. Praveen Kumar KV, Chiranjeevi P, Alam MS. Aripiprazole-induced transient myopia: A rare entity. Indian J Ophthalmol 2018;66:130-1.

8. Ikeda N, Ikeda T, Nagata M, Mimura O. Ciliochoroidal effusion syndrome induced by sulfa derivatives. Arch Ophthalmol 2002; 120:1775.

9. Postel EA, Assalian A, Epstein DL. Drug-induced transient myopia and angle-closure glaucoma associated with supraciliary choroidal effusion. Am J Ophthalmol 1996; 122:1 I0-2.

10. Lee JTL, Skalicky SE, Lin ML. Drug-induced Myopia and Bilateral Angle Closure Secondary to Zolmitriptan. J Glaucoma 2017;26:954-6. 